\title{
Educación emocional y centros de interés: cómo trabajar las emociones en educación infantil
}

\section{Emotional education and centers of interest: how to work with emotions in early childhood education}

DOI: $10.46932 / \operatorname{sjd} d v 2 n 2-050$

Received in: january 1st, 2020

Accepted in: March 30th, 2020

Marta Mendez Montoya

Graduada Educación Infantil

Institution: RG Formación

Calle Rosalía de Castro, 44, 30107 Murcia

Marta Pérez Martínez

Graduada Educación Infantil

Institution: RG Formación

Calle Rosalía de Castro, 44, 30107 Murcia

\author{
Ana Ruiz Alonso \\ Graduada Educación Infantil \\ Institution: RG Formación \\ Calle Rosalía de Castro, 44, 30107 Murcia \\ Jose María Rabal Alonso \\ Profesor ISEN Centro Universitario \\ Institution: Universidad de Murcia \\ Calle Campus Universitario, 12, 30100 Murcia \\ E-mail: josemaria.rabal@um.es
}

\section{RESUMEN}

Partiendo de un marco teórico, la educación emocional y las emociones positivas deben ser trabajadas en los niños y niñas. Más aún si se trata de la Educación Infantil, donde aún no comprenden bien o no saben gestionar las mismas, debido a su egocentrismo, entre otras dificultades que no les permiten ponerse en el lugar de los demás o resolver conflictos de forma positiva. En este artículo, planteamos una serie de actividades y técnicas para conocer y trabajar tanto las emociones como las emociones positivas, pudiendo éstas ayudar al alumnado en diversas situaciones de la vida cotidiana.

Palabras clave: Educación emocional, emociones positivas en infantil, actividades para la educación emocional.

\footnotetext{
ABSTRACT

Starting from a theoretical framework, emotional education and positive emotions should be worked on in children. Even more so if we are talking about Early Childhood Education, where they still do not understand well or do not know how to manage them, due to their egocentrism, among other difficulties that do not allow them to put themselves in the place of others or resolve conflicts in a positive way. In this article, we propose a series of activities and techniques to know and work both emotions and positive emotions, which can help students in various situations of everyday life.
} 
Key words: Emotional education, positive emotions in children, activities for emotional education.

\section{MARCO TEÓRICO}

Trabajar la inteligencia Emocional y educar en las emociones, debe ser unos de los objetivos prioritarios en la etapa de la Educación Infantil, ya que el niño inicia su escolarización con un desarrollo madurativo repleto de energía emocional, necesidad de comunicar sus sentimientos y emociones y falta de destreza en la utilización de los cauces adecuados de comunicación de dichas emociones y necesidades afectivas.

Para llevar a cabo los conocimientos actitudinales, sin olvidar que todos ellos se trabajan desde una perspectiva global e interdisciplinar, vamos a centrarnos en las emociones, demostrando su importancia en el desarrollo de los niños y niñas, ya que el conocimiento del desarrollo afectivo va a marcar la configuración de su personalidad, en esta etapa, pilar de su proceso de enseñanza y aprendizaje. Así como también de su desarrollo evolutivo.

El estudio de la emoción humana es controvertido, complejo y a la vez apasionante e integrador de los dominios biológicos, cognitivos y sociales del desarrollo humano (Vecina, 2006). Hablar de emociones desde una postura crítica y objetiva no es fácil, pues dicho concepto ha estado impregnado de características que, en gran medida, implican aspectos subjetivos (Fredrickson, 2001).

Bach y Darder (2002) promulgan que "las emociones derivan de sucesos internos o externos significativos y normalmente comportan algún tipo de alteración en el curso habitual de nuestra vida". (p.49). También, Goleman (1995) afirma que el término "emoción" se refiere a un sentimiento y a los pensamientos, los estados biológicos, los estados psicológicos y el tipo de tendencias a la acción que lo caracterizan (p.418). Por otro lado, Rotger (2017), considera las emociones como reacciones psicofisiológicas que representan modos de adaptación a ciertos estímulos del individuo cuando percibe un objeto, persona, lugar, suceso o recuerdo importante, preparándonos para una reacción.

Por otra parte, el Proyecto Spectrum, es un acercamiento a la Teoría de las Inteligencias Múltiples de Howard Gardner en 1983. Gardner propuso una visión pluralista de la mente así como una visión polifacética de la inteligencia. Garder aportó un método para trazar la variedad de capacidades que todos podemos, agrupándolas en ocho inteligencias: inteligencia lógico- matemática y inteligencia lingüística, inteligencia visual- espacial, Inteligencia cinestésica, Inteligencia musical, Inteligencia lingüísticoverbal, Inteligencia lógico- matemática, Inteligencia naturalista, Inteligencia intrapersonal e Inteligencia interpersonal.

Centrándonos en el tema que nos ocupa, haremos hincapié en las dos últimas:

Por un lado, la Inteligencia Intrapersonal se refiere a "la capacidad de conocernos, aceptarnos y adaptar la propia 
manera de actuar a este conocimiento" (Del Pozo, 2008, p. 53). Consiste en la capacidad para conocer aspectos internos de la persona, como son el acceso a la propia vida emocional y a la propia gama de sentimientos.

Reyes (2019) señala que una persona que desarrolla esta inteligencia, cuenta con una buena capacidad de autocrítica y autoestima y permite comprenderse y trabajar con uno mismo.

En cuanto a la Inteligencia Interpersonal, Sambrano (2016) la define como la capacidad para percibir y establecer diferencias entre los diversos estados de ánimo, motivaciones, sentimientos y emociones de otras personas.

Reyes (2019), afirma que esta esta inteligencia se construye a partir de la sensibilidad de empatizar con los demás, particularmente con sus estados de ánimo, temperamentos, motivaciones e intenciones. La inteligencia interpersonal permite comprender a los demás y trabajar con ellos.

Del Pozo (2008), destaca la importancia de esta capacidad debido a que los seres humanos viven en sociedad y no de manera individual, por ello, permite la relación con los demás, la comprensión de los sentimientos de otros para el mantenimiento de relaciones estables y la creación de roles dentro de un grupo.

Se pretende fomentar el desarrollo de estas inteligencias en los discentes que corresponde a la etapa de Educación Infantil, puesto que cada uno tiene una serie de capacidades para desarrollar sus fortalezas. Para ello hay que observar el contexto del alumno, tanto sus habilidades como sus debilidades.

Así, en relación a lo anteriormente mencionado y de acuerdo con Cruz (2014), consideramos también la importancia de poner al alcance de los alumnos todos los tipos de lenguaje que les sirvan para expresar su mundo emocional: El lenguaje del cuerpo, el lenguaje musical, el lenguaje plástico, el lenguaje verbal, el lenguaje no verbal y el juego simbólico. Y por tanto, establecer un buen camino para el descubrimiento de las emociones a través de la expresión lingüística y de la expresión corporal, con el juego y la experimentación como medio de enlace en las actividades desarrolladas en el aula

La inteligencia emocional ha ocupado un lugar a lo largo de la historia, pues diferentes situaciones, han provocado en la humanidad una serie de emociones que hacen recordar ese hecho de una forma positiva o negativa. Aquí es donde se hace latente el concepto de inteligencia emocional y emociones per se.

Daniel Góleman define Inteligencia Emocional como la capacidad de establecer contacto con los propios sentimientos, discernir entre ellos y aprovechar este conocimiento para orientar nuestra conducta, y la capacidad de discernir y responder adecuadamente a los estados de ánimo, temperamento, motivaciones y deseos de los demás. (Goleman, 1996). 
Goleman (1998) en su teoría de la inteligencia emocional defiende que las emociones conllevan un movimiento. Esto quiere decir que necesitamos una aptitud para realizar una tarea, una capacidad, predisposición. Una emoción que supone una respuesta ante una situación, posteriormente habrá que ver si esa emoción es positiva, negativa o cómo la resolvemos. Esta teoría supone un componente físico del niño.

Cierto es que nuestro cerebro absorbe todo lo que ocurre a su alrededor, por ello es importante establecer un apropiado aprendizaje de las emociones y en concreto proponer experiencias positivas, pues "recordaremos siempre aquellas que nos han marcado" (Mora, 2016).

Por otro lado, Seligman y Csiks zentmihalyi (2000) establecen que la psicología clásica en la enfermedad ha descuidado los aspectos positivos e internos del individuo, como son el bienestar, la satisfacción, la esperanza, el optimismo y la felicidad, ignorándose los beneficios que éstos presentan para las personas; Así, los investigadores señalan disminuir los componentes emocionales negativos, cuando resulta igualmente valioso promover el cultivo de las emociones positivas (Barragán, Ahmad y Morales, 2014). En resumen, el efecto de una emoción positiva significa realizar una acción que va a perdurar en el tiempo, y que el alumno utilizará como recurso en diversas situaciones, adquiriendo así una mayor autoestima y motivación (Fredrickson, 2002).

\section{COMPETENCIAS O CAPACIDADES DE LA INTELIGENCIA EMOCIONAL}

Begoña Ibarrola (2009), propone la siguiente clasificación de competencias para trabajar tanto en el aula como en casa:

- Conocimiento de las propias emociones o autoconciencia: Capacidad de reconocer un sentimiento en el mismo momento en el que aparece, para ello el alumno debe aprender a ser consciente de sus propias emociones, identificarlas correctamente y ponerlas nombre, y por último comunicarlas de forma verbal y no verbal.

- Capacidad de regular las emociones o autocontrol: Ibarrola la define como la capacidad que permite controlar la expresión de nuestros sentimientos y emociones, y adecuarlos al momento y al lugar. Esto se conseguirá si trabajamos estrategias de autocontrol emocional, expresión adecuada de emociones y tolerancia a la frustración.

Se trata de comprenderlas y expresarlas adecuadamente, construyendo progresivamente su tolerancia a la frustración, haciendo frente a estos sentimientos positivamente.

- Reconocimiento de las emociones ajenas o empatía: Consiste en la capacidad de entender lo que otras personas sienten, saber ponerse en su lugar, sintonizar con las señales sociales que indican lo que los demás quieren o necesitan. 
Trabajar en el aula tanto la comunicación verbal como no verbal y la escucha, serán dos estrategias fundamentales para establecer una relación emocional hacia los demás que haga superar al niño su etapa egocéntrica.

- Control de las relaciones o destreza social: que implica dirigirse a las personas, sabiendo relacionarse y entenderse con ellas. Esta relación debe centrarse en el desarrollo de la asertividad y en la resolución pacífica de conflictos.

- Capacidad de motivarse a sí mismo o motivación intrínseca: entre las que Ibarrola destaca la autoestima, motivación y actitud positiva y optimista.

\section{BENEFICIOS DE LA EDUCACIÓN EMOCIONAL EN LAS AULAS}

Trabajar la educación emocional en clase permite adquirir destrezas básicas que sirven y ayudan a desenvolvernos en la sociedad y si los niños comprenden y controlan sus emociones logran aprendizajes significativos.

Muchos expertos señalan que lo ideal es que la educación emocional se aplique en las primeras etapas escolares y así se podrán lograr resultados satisfactorios.

Así la evidencia científica plasmada en trabajos anteriores como los llevados a cabo por Alonso, Martínez, Alonso, Montoya y Romero (2020), sintetizan y extraen la trascendencia de los beneficios de la educación emocional (estudiado a su vez por González, 2020). Señalamos a continuación, algunos beneficios de introducir la educación emocional en las aulas:

- Habilidades sociales necesarias para relacionarnos con los demás. Somos seres sociales. Vivimos en comunidad, los trabajos son en equipo, cooperamos y nos relacionamos continuamente con otras personas. El hecho de saber ser empático, ponerse en el lugar del otro, es una habilidad que será fundamental en la vida.

- Regulación emocional y autoconocimiento. Saber gestionar nuestras emociones es fundamental. Es decir, ser consciente de lo que sentimos y por qué lo sentimos, nos permitirá afrontar diferentes situaciones con más seguridad y confianza.

- Habilidades vitales que nos ayudarán a afrontar los contratiempos de la vida. A lo largo de la etapa estudiantil, o en el resto de la vida, nos enfrentaremos a situaciones inesperadas o difíciles. La inteligencia emocional nos puede ayudar a saber superarlas y afrontarlas

Por lo tanto, las implicaciones de las emociones en el ámbito educativo creemos que son amplias, ya que se trabajan aspectos como el propio conocimiento de las emociones, aprender a expresar los sentimientos propios y de los demás, tener empatía hacia el resto de compañeros y sus emociones. Todas 
estas capacidades que se desarrollan al trabajarlas, ayudan a que mejore la inclusión en las aulas, el clima en el grupo-clase y que poco a poco, conforme se vayan formando emocionalmente cada vez en edad más temprana, estos alumnos conseguirán que se formen grandes personas y más felices.

Por ello, es muy importante que los maestros y maestras de Educación Infantil, sepan trabajar en el aula, aspectos emocionales, relacionándolos con los sentimientos, deseos, vivencias, conflictos y las necesidades e intereses de los infantes. De esta manera, ayudaremos a construir una estructura personal adecuada y dotándoles de capacidades para relacionarse socialmente.

Como docentes y tras nuestro paso por varios centros educativos, proponemos la siguiente batería de actividades concretas, para trabajar las emociones positivas en la etapa de Educación Infantil, así como controlar y equilibrar emociones negativas y el paso de una emoción a otra, para conseguir un adecuado desarrollo en el proceso de enseñanza y aprendizaje.

\section{BATERÍA DE ACTIVIDADES.}

\subsection{LA BOTELLA DE LA CALMA}

La primera actividad consiste en realizar una botella de la calma, que se utilizará para el posterior rincón de la calma y para la relajación diaria, con los alumnos en el aula.

Área: Conocimiento del entorno.

Objetivos didácticos:

- Reflexionar sobre nuestros pensamientos y emociones.

- Favorecer la relajación y el autocontrol.

- Fomentar la capacidad de concentración.

Contenidos didácticos:

- Fomento del control y reflexión sobre sus emociones.

- Realización de una manualidad para conseguir la relajación en los niños.

La duración de esta actividad será de 2 horas, ya que consta de dos partes y se realizará la primera parte en las mesas de trabajo de los alumnos y la segunda en una mesa auxiliar de la clase.

Las dos partes de esta actividad son:

La primera se trata de escribir en la portada de una cartulina blanca, doblada por la mitad "MI RECETA". Debajo tienen que dibujar una botella, y al final de la cartulina poner "LA BOTELLA DE LA CALMA".

A continuación, se abre la cartulina, y en la página de la derecha escriben "INGREDIENTES", y debajo: pegamento, purpurina, colorante y agua.

en palabras 
Conforme van terminando, los niños van a la mesa donde se hace la botella de la calma, y en esta segunda parte cogen su botella, se sientan y esperan su turno, ya que la actividad de hacer su propia botella de la calma se realiza de dos en dos, pues necesitan mucha atención a la hora de añadir todos los ingredientes y las cantidades correctas. Dentro de esta segunda parte hay que seguir varios pasos:

- El primer paso es llenar la botella con agua templada de un barreño.

- El segundo paso es echar el pegamento. Cuando haya echado el pegamento, el niño tendrá que cerrar la botella y moverla. Mientras que un niño echa el pegamento, el otro, llena la botella de agua.

- El tercer paso es elegir de qué color quiere el colorante. Una vez elegido, el niño echa dos gotitas de colorante en la botella, la cierra y la agita. El otro niño, hace el paso anterior.

- El cuarto paso es elegir de qué color quiere la purpurina, echar tres cucharaditas en la botella, cerrarla y moverla. El otro niño mientras que se está haciendo este paso, estará haciendo el paso anterior.

- El último paso es elegir el color de las estrellas que se le van a añadir a las botellas. Tienen que abrir la botella y añadir el color de las estrellas que quieran, volviéndola a cerrar y moviéndola. El compañero que iba después de éste, estaría realizando el paso anterior, y una vez que éste ha terminado, sería el turno de los dos niños siguientes.

Los alumnos irán dejando sus botellas en una mesa y posteriormente se precinta el tapón de la botella y se decora con fieltro y un lazo de cinta. Véase en la Figura 2.

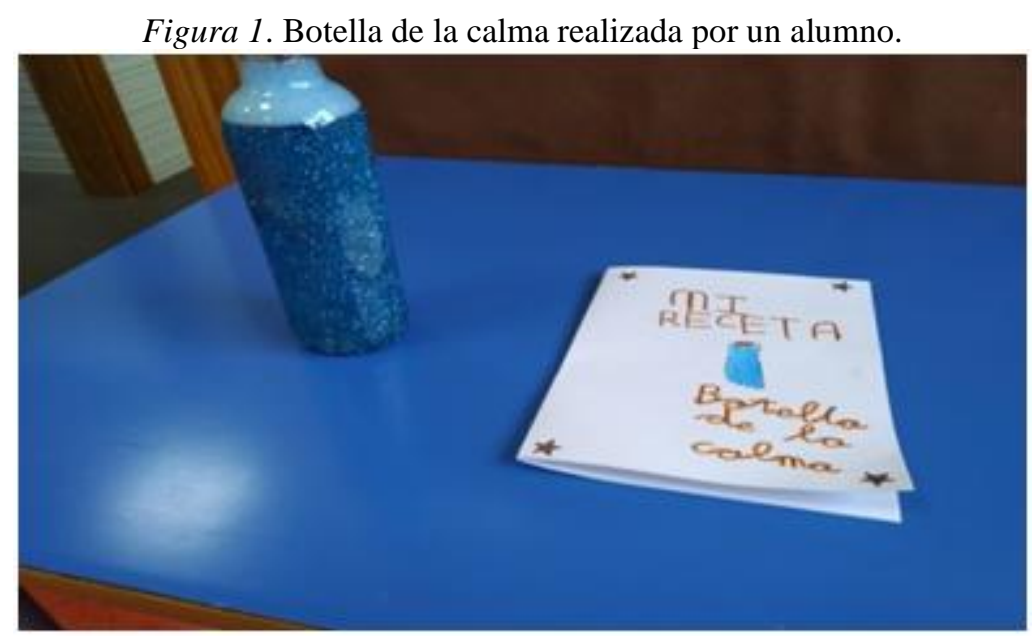

Fuente: elaboración propia.

En la Figura 1 se puede observar la imagen de la botella de la calma y la receta realizada por un niño de 5 años.

En cuanto a las adaptaciones, la primera parte de esta actividad se ha adaptado para la alumna A, la cual pondrá su nombre y se le pondrá en un folio a parte MI RECETA, para que lo pueda copiar, con respecto a la escritura de LA BOTELLA DE LA CALMA la maestra se lo pondrá con puntitos para que 
lo repase con lápiz y luego con rotulador, por último los ingredientes los escribirá la maestra y ella decorará la ficha (Ruiz, 2020, p. 9).

\subsection{EL RINCÓN DE LA CALMA}

Área: Conocimiento de sí mismo y autonomía personal.

Objetivos didácticos:

- Reconocer las emociones.

- Aceptar la emoción que sienten.

- Aprender a gestionar y regular sus emociones.

- Comprender distintas herramientas y estrategias para gestionar sus emociones.

Contenidos didácticos:

- Reconocimiento, aceptación y gestión de las emociones.

- Conocimiento sobre las diferentes estrategias y herramientas para resolver sus emociones.

Esta actividad se ha llevado a cabo con aquellos niños que muestren algún sentimiento de los que se van a trabajar, los cuales serían: ira, alegría, tristeza, miedo y asco.

La duración de esta actividad se desarrolla en 30 min por cada niño que pase por el rincón y el lugar es en el rincón de la calma (se puede ver en la Figura 4)

Figura 2. Lugar donde se realizará. Fuente: elaboración propia

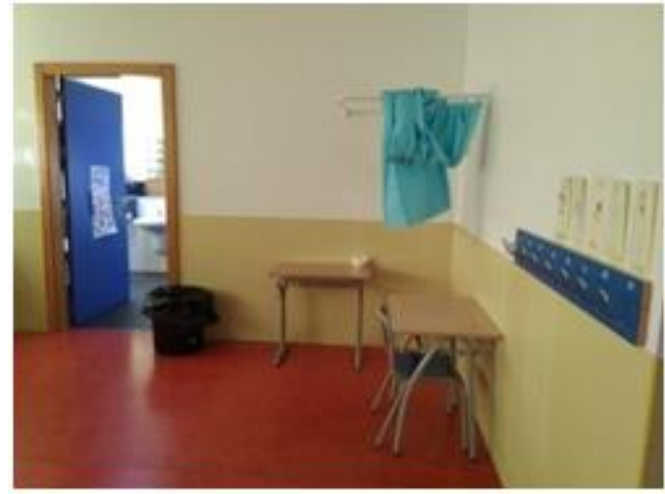

Figura 3. Rincón de la calma. Fuente: elaboración propia. 


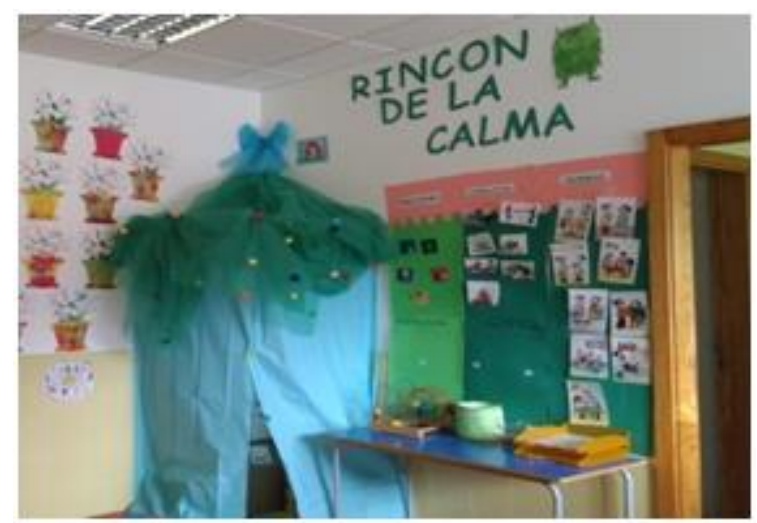

En la Figura 2 y 3 se puede observar la transformación que se realizó para implantar el rincón de la calma.

Para comenzar a trabajar con las emociones, se va a visionar la película "Del Revés (Inside Out)", así como el visionado de la presentación de las emociones, para recordar cómo se siente cada una y saber reconocer a través de los personajes de la película, cuál es la emoción que sienten.

El visionado se realizará en el primer paso del rincón de la calma, antes del reconocimiento de la emoción. Para ello, se dispondrá de una tablet con acceso directo a los vídeos sobre las 5 emociones que se van a trabajar, cuyo autor es Disney España y están subidos a la plataforma de Youtube el 26 de noviembre de 2014.

Cada día va un alumno al rincón de las emociones, la elección de dicho niño dependerá o bien del orden de lista, o si hay algún comportamiento disruptivo, iré anotando qué alumno ha pasado por el rincón, con la finalidad de que todos tengan la oportunidad de participar en el mismo.

Una vez que los alumnos ya han visto los cortos sobre cómo se siente cada emoción, se disponen a elegir qué emoción sienten, para ello tendrán un mural con las imágenes de las emociones de la película “Del Revés (Inside Out)”, véase en la Figura 5.

Figura 4. Imágenes de los personajes de la película Inside Out.

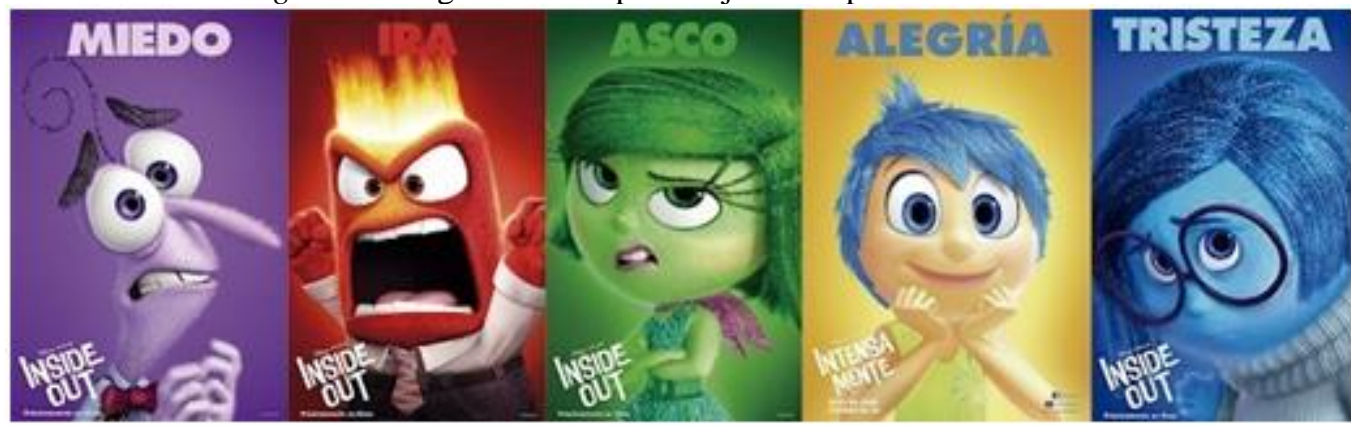

Fuente: Pintado (2015). 
Esta imagen se presentará recortada, de manera que las emociones estén individuales y los alumnos tendrán que relacionar la emoción que sienten con la de la imagen.

Además de estas imágenes, también habrá imágenes de niños que representen dichas emociones, como se puede ver en la Figura 5.

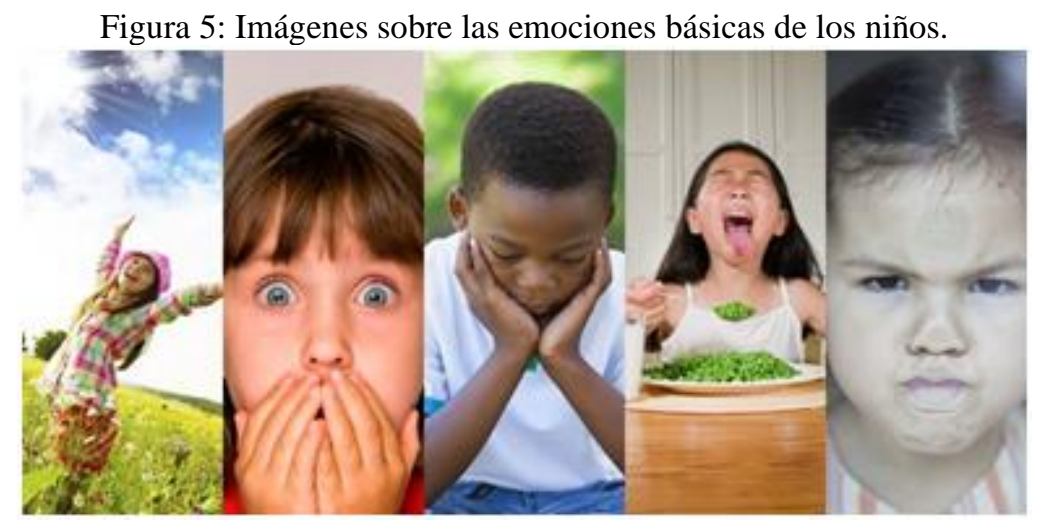

Fuente: Medina (2020)

A diferencia de las imágenes anteriores de la película de "Inside Out", donde las tienen que reconocer al entrar al rincón, con las fotos de los niños expresando las 5 emociones, tendrán que seleccionarlas una vez que salgan del rincón, para que ellos mismos observen el cambio de emoción.

Si han incumplido alguna norma, además de decidir qué emoción sienten al entrar al rincón, también deben reconocer ellos mismos la norma que han incumplido. Estas normas serán las normas básicas de la clase que además de estar en la asamblea, estará impresas en pequeño en el Rincón de la calma, para que así puedan seleccionarlas.

Por lo tanto, podemos ver que el Rincón de la calma, tiene varias fases:

La primera como ya he mencionado es el reconocimiento de la emoción y de la norma incumplida.

En la segunda fase hay varias actividades artísticas como son pintar piedras con témpera líquida, colorear mandalas con rotuladores, lápices de colores o ceras, a elección del alumno, pintar en el cartón de huevos, completar dibujos haciendo papelitos de papel de seda...

En la tercera fase, el alumno pasa al interior del rincón, al que se entra por medio de una cortina, tiene una ventana para que desde fuera se pueda ver lo que el alumno hace dentro de la cabaña, pero sin que el alumno pueda ver lo que sucede fuera para que no se despiste. Dentro del rincón, tendrá una imagen de la técnica de la tortuga, véase en la Figura 7. También papel de burbujas para que las exploten y le relaje, una pelota antiestrés, una bola de nieve, relojes de arena y su peluche para abrazarlo, se le pedirá a los padres que lleven uno tanto para la relajación, como para el rincón de la calma, para que puedan establecer un vínculo con ellos, además cogerán también su botella de la calma, creada anteriormente. 


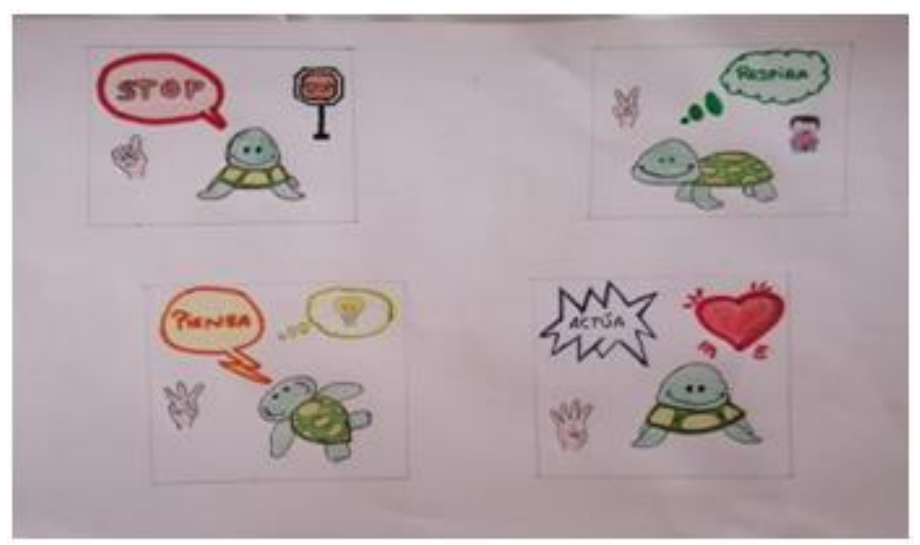

Fuente: elaboración propia.

Este mural estará dentro del rincón de la calma y les servirá a los niños para reflexionar sobre lo que deben hacer cuando les ocurra un problema. Siguiendo los cuatro pasos, parar, respirar, pensar y por último actuar.

Por último, el niño sale de la cabaña y en el caso de estar en el rincón por el incumplimiento de una norma, tendrá que indicar en la ruleta de la resolución de conflictos (véase en la Figura 8) cómo tendría que haber actuado ante cierta situación.

Las opciones que da la ruleta de resolución de problemas son: hablar, disculparse, esperar y tranquilizarse, realizar otra actividad, resolver el problema jugando a piedra, papel o tijera y reconocer la emoción que siente. Entre todas ellas, los niños tendrán que elegir de qué opción podrían haber reaccionado ante cierto conflicto y qué solución podrían utilizar si les volviera a pasar una situación similar (Ruiz, 2020, p. 11).

Figura 7. Ruleta de resolución de conflictos.

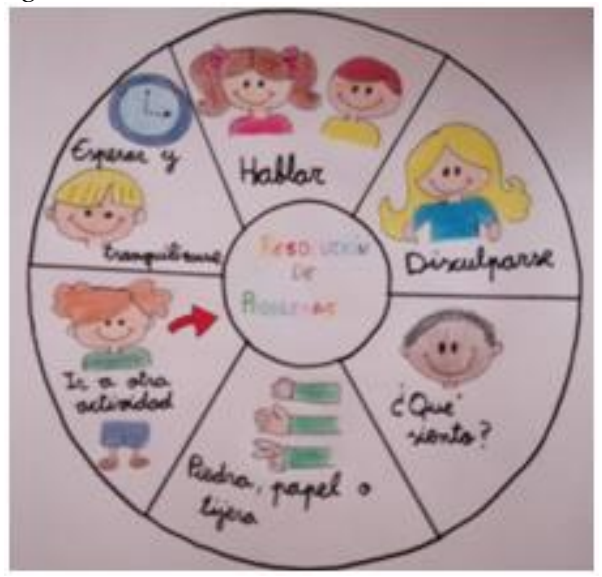

Fuente: elaboración propia.

El recorrido de las canicas

Área: Lenguajes: comunicación y representación 
Objetivos didácticos:

- Favorecer la relajación y el autocontrol.

- Fomentar la capacidad de concentración.

- Relacionar los colores con sus emociones.

- Expresar sus emociones a través del lenguaje oral y el plástico.

\section{Contenidos didácticos}

- Realización de una manualidad para conseguir la relajación en los niños.

- Relación de la manualidad con nuestras emociones, relacionándolo a la vez con los colores del libro del monstruo de los colores.

Esta actividad durará una sesión de una hora y media, en la que la primera parte se realizará en las mesas de trabajo del alumnado y la segunda parte se llevará a cabo en la asamblea.

En esta actividad hay una parte de trabajo manual y otra en la que tienen que exponer sus sentimientos relacionados con la actividad que han realizado anteriormente.

Lo primero que se va a realizar es leer el cuento "El monstruo de los colores", para recordarle las emociones que experimenta el protagonista de la historia, así como los colores con los que se representa cada emoción.

Además de trabajar las emociones del Rincón de la calma (alegría, ira, miedo, tristeza y asco), se añadirá la emoción del amor.

La primera parte consiste en, situar a los alumnos en sus mesas de trabajo, habiendo así grupos de cinco niños. Cada uno tendrá una caja de zapatos, de talla propia de adulto, además de una cartulina blanca tamaño A4. En sus mesas de trabajo hay 6 botes con pintura de los colores que representa el cuento de "El monstruo de los colores", es decir, rosa, amarillo, verde, rojo, azul y gris. En cada bote hay 5 canicas.

Pero antes de darles los materiales, se explicarán todos los pasos que tienen que seguir.

Primero, se les enseñará con un ejemplo cómo tienen que coger la canica dentro del bote de pintura (el color que elijan, deben relacionarlo con la emoción que sienten en ese momento) con una cucharita de plástico y dejarla sobre la cartulina blanca, dentro de la caja de zapatos.

Se mostrará un ejemplo con la emoción de la alegría, por lo tanto cogeríamos la canica del bote con pintura de color amarillo, se les enseña que si hemos elegido ese color, tendremos que mover la caja de una forma determinada, en este caso:

Para el color amarillo, que representa la alegría le diremos que tienen que imitar una sonrisa, que para ello tienen que realizar una curva como si fuera una $\mathrm{U}$, primero tenemos que bajar y luego tenemos que subir. 
A continuación, escribirán el nombre de la emoción que sienten, como puede verse en la Figura 8.

Figura 8. Niña realizando la actividad número 3.

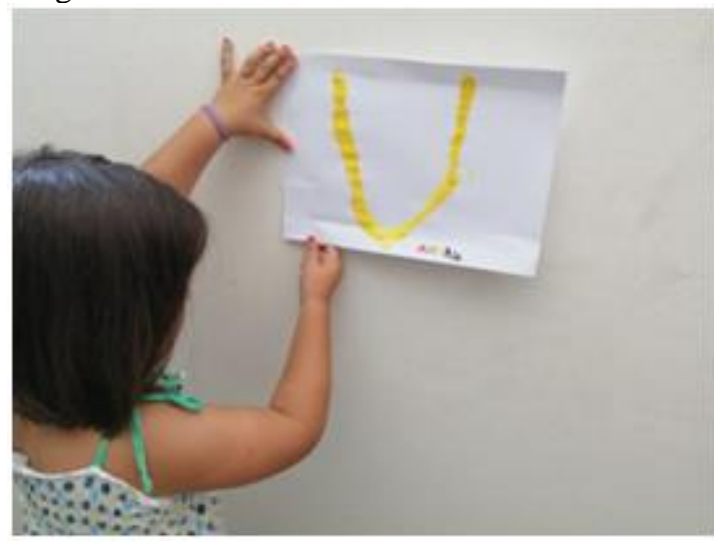

Fuente: elaboración propia. 
Le haremos un ejemplo con el resto de emociones y de colores, para los cuales los movimientos serán los siguientes:

Para el color azul, que representa la tristeza les diremos que tienen que imitar una carita triste, y para ello tendrán que realizar una curva, pero en este caso al contrario de la $\mathrm{U}$, donde primero tendremos que subir y luego bajar. Como si fuera una A, pero sin cerrar la puerta.

Para el color verde, que representa la calma, los niños tendrán que mover la caja de zapatos de un lado a otro, es decir, de derecha hacia izquierda, despacito.

Para el color rojo que representa el enfado, tendrán que hacer círculos con la caja.

Para el color gris que representa el miedo, los niños tendrán que dar golpecitos despacito, como si fueran saltitos hacia arriba de la caja.

Para el color rosa que representa el amor, los niños tendrán que realizar movimientos hacia delante y hacia atrás simulando los latidos del corazón.

Cuando hayan terminado de realizar el recorrido con las canicas, tendrán que sacar la canica con otra cuchara nueva, para que ésta no esté manchada de pintura y ensucie el trabajo y escribir en mayúscula el nombre de la emoción que sienten.

En la segunda parte de la actividad los niños tienen que decir la emoción que sienten y para ello qué color han utilizado, los movimientos que han realizado con la caja y las canicas y por qué se sienten así.

En esta parte los niños salen a la asamblea por equipos de trabajo y van explicando sus sentimientos. El resto de niños estarán en la asamblea, pero las cajas con el recorrido de las canicas estarán en sus mesas, y cuando un equipo acabe, tendrá que ir a su mesa a dejar las cajas cada uno en su sitio, y el siguiente equipo, por el contrario, tendrá que ir a cogerlas de sus mesas de trabajo.

Actividad del recorrido de las canicas con el monstruo de los colores:

En esta actividad hay una parte de trabajo manual y otra en la que tienen que exponer sus sentimientos relacionados con la actividad que han realizado anteriormente.

Lo primero que se va a realizar es leer el cuento "El monstruo de los colores", para recordarle las emociones que experimenta el protagonista de la historia, así como los colores con los que se representa cada emoción.

Además de trabajar las emociones del Rincón de la calma (alegría, ira, miedo, tristeza y asco), se añadirá la emoción del amor.

Se mostrará un ejemplo con la emoción de la alegría, por lo tanto cogeríamos la canica del bote con pintura de color amarillo, se les enseña que si hemos elegido ese color, tendremos que mover la caja de una forma determinada. 
A continuación, escribirán el nombre de la emoción que sienten (Ruiz, 2020, p. 14).

\section{TÉCNICAS PARA EQUILIBRAR NUESTRAS EMOCIONES}

\subsection{EL SEMÁFORO.}

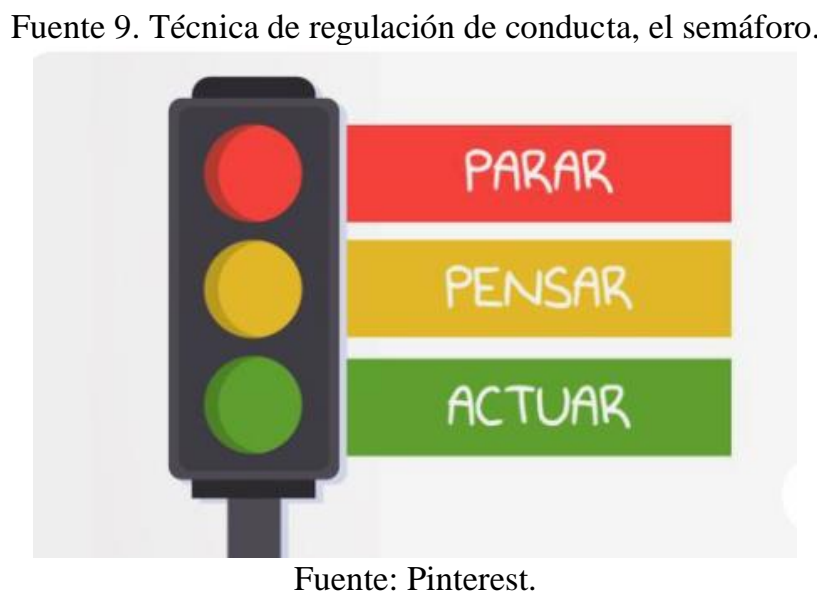

En un primer momento, debemos asociar los colores del semáforo con ciertas emociones o sentimientos y estados de ánimo, por ejemplo: el rojo con la ira, el amarillo con el pensamiento y el verde con la calma.

En segundo lugar, debemos realizar un mural para tener presente nuestro semáforo y qué representa cada color. De modo que:

La luz roja indica que paremos para poder tranquilizarnos, pensar y actuar.

Como indicamos con la luz roja, pasamos a la luz amarilla, donde pensamos una solución al problema que tenemos o de dónde puede venir la ira y cómo podemos llevarla a un estado positivo. Así como comprender las consecuencias que pueden tener nuestros actos.

De este modo pasamos a la luz verde, donde experimentamos una calma y serenidad, para poder tomar decisiones de forma correcta y ser consecuentes con nuestros actos.

Esta técnica es una forma de reflejar al niño que desde una emoción negativa seguramente venga una consecuencia negativa, pero si paramos nos calmamos y vemos el "lado bueno de las cosas", tomaremos decisiones que nos lleven a consecuencias positivas. Así como ayudar a gestionar su ira. 


\subsection{LA TORTUGA}

Figura 10. Técnica de la tortuga.

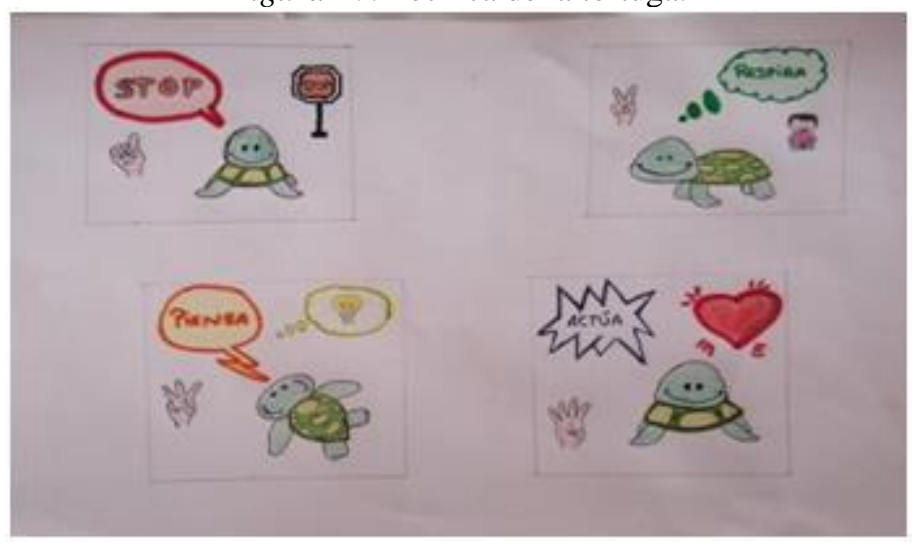

Fuente: elaboración propia.

Esta técnica es una herramienta que ayuda a controlar la agresividad, rabietas, o impulsos por parte de los niños y niñas. Consiste en contar una pequeña historia que ayuda al niño a "meterse en el caparazón de la tortuga", mientras siente esas conductas poco inapropiadas, para que desde la calma y la tranquilidad, puedan pensar las soluciones a sus conflictos.

"Tortuga" será la palabra clave que se utilice para indicar que debemos parar y realizar la técnica, que previamente debe ser explicada en clase. Por otro lado, posteriormente sería necesario realizar una pequeña relajación, debido al estado de tensión que puede haber sufrido el alumno.

\subsection{MANDALAS MINDFULNESS. "PARA SENTIRSE BIEN”.}

Dibujar un mandala se asocia a la práctica de mindfullness, se acompaña de frases motivadores y sólo necesitamos que los alumnos se centren en los sentidos. Sentir el tacto de la hoja, el sonido del lápiz al dibujar, y ser conscientes de lo que estamos dibujando aquí y ahora.

Figura 11. Libro de mandalas. Fuente: Foto de elaboración propia, (librería Cervantes).

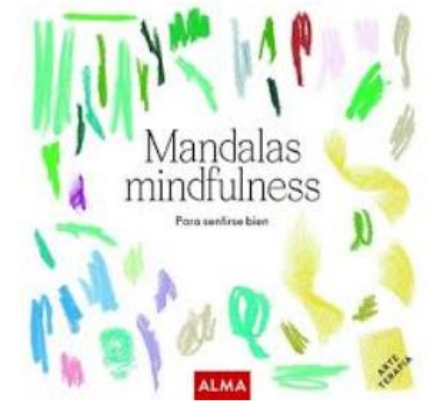




\subsection{LA CAJA DE LAS EMOCIONES:}

Una de las formas con las que podemos trabajar las emociones en clase es a través de un juego denominado «La caja de las emociones». Su funcionamiento es simple y puede ser adaptado a las características o necesidades de cada clase. Se tiene que prepara una caja (de plástico, cartón, etc.) con todo nuestro grupo de alumnos y en ella se escribe el nombre de las diferentes emociones, junto con algún dibujo representativo. Esta caja debe estar situada en un lugar visible del aula y ser accesible a todos los alumnos. Además, se dispondrá de papel en forma de pequeñas notas para que los alumnos puedan escribir en ellos sus mensajes. El objetivo de este juego es conseguir que nuestros alumnos y alumnas aprendan a comunicarse emocionalmente. A partir de estas comunicaciones individuales podemos profundizar en el conocimiento de las diferentes emociones (alegría, tristeza, desesperanza, rencor, etc.). De esta forma se logra una mayor inteligencia emocional y enseñar nuevas formas de afrontamiento de conflictos y canalización adecuada de los sentimientos que la acompañan. Con ello también estamos efectuando un trabajo preventivo respecto a posibles nuevos conflictos (Imágenes educativas, 2019).

Figura 12. Caja de las emociones.

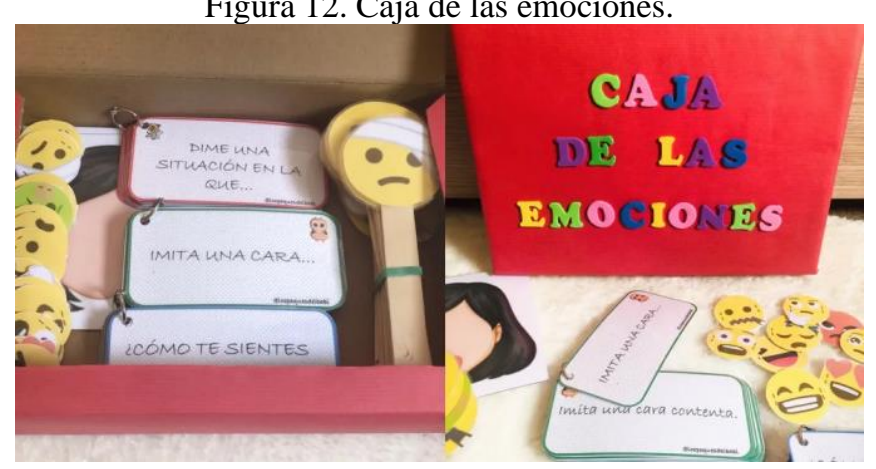

Fuente: Orientación Andújar (2019).

\subsection{EL ACUSADO:}

Esta dinámica es ideal para que los profesores eduquen a sus alumnos en control emocional. En el aula, el profesor debe leer en voz alta el comienzo de esta historia.

"Va Pepe muy contento por el parque, cuando de repente ve a Rafa viniendo a su encuentro. Rafa tiene una mirada muy rara. Pepe se pregunta qué le estará pasando. Se acercan y se saludan, pero inmediatamente Rafa comienza a gritar. Dice que Pepe le ha hecho quedar muy mal con los otros chicos del barrio, que es mal amigo, que tiene la culpa de todo lo que le pasa. Entonces Pepe...”.

Una vez leído el cuento, los alumnos deben pensar de forma individual cómo actuarían se encontraran en la situación en la que está Pepe. Después, se comparten las respuestas y se clasifican en dos grupos: las que permiten la conciliación y buscan un camino pacífico y las que promueven un mayor 
conflicto. En forma de debate, se llega a la conclusión de por qué las primeras son mejores que las segundas (Imágenes educativas, 2019).

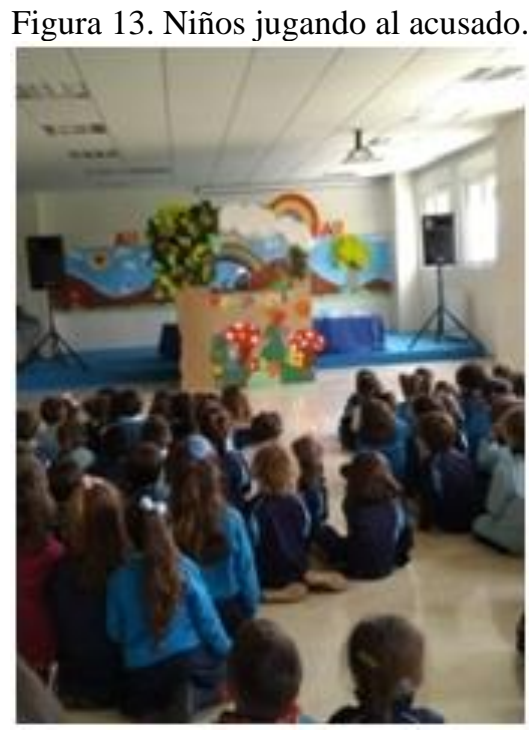

Fuente: Elaboración propia.

\section{CONCLUSIÓN}

Para finalizar con el artículo, es imprescindible, partir de la idea de para qué queremos trabajar la educación emocional en las aulas, y concretamente qué nos aportan las emociones positivas en el trato diario entre docentes y discentes.

Como hemos visto a lo largo del artículo, las emociones inducen a generar habilidades que les serán de gran utilidad en diversas situaciones a los niños y niñas, a lo largo de su proceso de enseñanza y aprendizaje. Puesto que el niño, pasa de un entorno a priori seguro como es el de su núcleo familiar a otro de gran envergadura, donde va a tener que lidiar con sus iguales y con adultos que pronto se convertirán en su referencia.

Para ello, debemos dedicar un tiempo, bien de forma puntual o bien de forma anual, a trabajar diferentes capacidades, competencias, inteligencias... con diferentes actividades, técnicas, etc. que ayuden a conocer al alumno diversas emociones y cómo saber gestionarlas en el día a día.

Para ello, hemos propuesto una serie de actividades y técnicas para la etapa de Educación Infantil, y así conocer qué percepción tienen los alumnos de sus emociones y cómo pueden resolver tanto conflictos internos como externos. Ya que debemos dejarles la opción de que gestionen sus propias emociones, partiendo de un conocimiento previo y una supervisión del adulto, en este caso el docente.

Las emociones no son ni malas ni buenas, según como hagamos una gestión de las mismas obtendremos un resultado u otro, de ahí el plantear las emociones positivas, puesto que será más beneficioso resolver un conflicto de forma positiva y entre todos los compañeros, guiado por el maestro. 
Podemos hacer que un niño pase de un estado negativo a una emoción positiva, con diferentes actividades, manualidades, expresando nuestros sentimientos... siempre respetando su espacio y su situación.

El docente debe ser un gran ejemplo en cuanto al aprendizaje de las emociones, pues es el referente de los discentes durante su jornada escolar. De modo que el estado de ánimo del docente también puede influir en en el aprendizaje de los niños y niñas. 


\section{REFERENCIAS BIBLIOGRÁFICAS}

Bach, E. y Darder, P. (2002). Sedúcete para seducir. Vivir y educar las emociones. Barcelona: Paidós.

Cruz, P. C. (2014). Creatividad e Inteligencia Emocional.(Como desarrollar la competencia emocional, en Educación Infantil, a través de la expresión lingüística y corporal). Historia y comunicación social, 19, 107-118.

Del Pozo, M. (2008). De qué inteligencias hablamos. Cuadernos de pedagogía, 376, 52- 54.

El semáforo, una técnica para regular la ira. Aula de innovación educativa. No (258), 2017. PP. 62

Fredrickson, B.L. (2001). The role of positive emotions in positive psychology.The broaden-and-build theory of positive emotions. American Psychologist, 56 (3), 218-226.

Goleman, D. (1995). Inteligencia emocional. Barcelona: Kairós.

Gonzalez, M. (2020). Una microsociedad llamada aula.

Ibarrola, B. (2009). Crecer en emociones. Madrid: S.M.

Imágenes Educativas (2019, 28 de enero). Actividades para trabajar las emociones con niños [Mensaje en un blog]. Obtenido de: https://www.imageneseducativas.com/actividades-para-trabajar-las-emocionescon-ninos/\#comments

Orientación Andújar (2019, 23 de octubre). La cajita de las emociones [Mensaje en un blog]. Obtenido de: https://www.orientacionandujar.es/2019/10/23/educacion-emocional-la-cajita-de-las-emociones/

Rotger, M. (2017). Neurociencias y Neuroaprendizajes: las emociones y el aprendizaje, nivelar estados emocionales y crear un aula con cerebro. Córdoba: Editorial Brujas.

Ruiz, A. (2020). Actividades artísticas para el desarrollo de la educación emocional. Murcia: Unicersidad de Murcia.

Sambrano, J. (2016). Inteligencias múltiples en los niños: Detección y estimulación de talentos tempranos para un desarrollo integral del niño. Felgris Araca.

Schneider, M. Robin, A. "Técnica de la tortuga un método para el autocontrol de la conducta impulsiva". Valencia. Editorial Promolibro. PP. 127- 164. 1992

Vargas, E. M. R. (2019). Inteligencias múltiples en Educación infantil. Círculo Rojo.

Vecina J., M.L. (2006). Emociones positivas. Papeles del Psicólogo, 27(1), 9-17. 